\title{
Biophysical profile and modified biophysical profile in predicting the fetal outcome
}

\author{
V. G. Vanamala ${ }^{1}$, Aruna Rachel ${ }^{1 *}$, Sushil Pakyanadhan ${ }^{2}$, Sudeep Abraham P. ${ }^{3}$
}

\begin{abstract}
${ }^{1}$ Department of Obstetrics and Gynecology, VRK Womens Medical College and Hospital and Research Centre, Hyderabad, Telangana, India

${ }^{2}$ Department of Pathology, ${ }^{3}$ Department of Surgery, Shadan Institute of Medical Sciences, Hyderabad, Telangana, India
\end{abstract}

Received: 18 July 2018

Accepted: 23 July 2018

\section{*Correspondence:}

Dr. Aruna Rachel,

E-mail: arura_pak@yahoo.com

Copyright: (c) the author(s), publisher and licensee Medip Academy. This is an open-access article distributed under the terms of the Creative Commons Attribution Non-Commercial License, which permits unrestricted non-commercial use, distribution, and reproduction in any medium, provided the original work is properly cited.

\begin{abstract}
Background: Baby's well-being in utero is often done by using a cardiotocograph (CTG) machine, which assesses the baby's heart beat pattern as well as the mother's uterine contractions. However, lowered fetal movements sometimes may be fatal for the baby. Thus, the biophysical and the modified biophysical profile have been introduced.

Methods: 242 patients with over 34 weeks of gestation and with one or more risk factors were included in the study. After taking the demographic details, the patients were subjected to detailed physical and clinical evaluation. Modified BPP was done on all the patients. Index of acute fetal hypoxia the NST was done along with the cardiotocograph (CTG). Amniotic fluid volume was calculated.

Results: According to the fetal non-stress test, majority of the patients (70.7\%) were reactive while $29.3 \%$ were nonreactive. Most of the patients had an amniotic fluid index in the normal range i.e. between $8-<25,18.6 \%$ ) had an AFI value of $<6 \mathrm{~cm}$ while $13.6 \%$ had between $6-<8$. Among the babies with reactive NST, non-reactive NST and AFI $\leq 5$, the most common outcome was low birth weight. APGAR score $<7$ was observed in $11.1 \%, 13.1 \%, 20 \%$ among Reactive NST, Non-reactive NST and AFI $\leq 5$ respectively.

Conclusions: Present study shows that BPP and MBPP are both comparable to each other, therefore, MBPP, being an easier test can be substituted for BPP.
\end{abstract}

Keywords: Biophysical profile, Fetal outcome, Modified biophysical profile, Pregnancy

\section{INTRODUCTION}

A baby's wellbeing in utero is often done by using a cardiotocograph (CTG) machine, which assesses the baby's heart beat pattern as well as the mother's uterine contractions. However, this is not very reliable test. In addition to the above, it is important to measure the fetal movements as well. This is especially useful to predict the fetal hypoxia. Lowered fetal movements sometimes may be fatal for the baby. One of the scenarios is that if there is a less oxygen supply to the fetus, the movements would be reduced. Thus, the biophysical and the modified biophysical profile have been introduced. In the year 1980, Manning et al, first described the use of fetal monitoring by including 5 variables such as of breathing, fetal movement, fetal tone, amniotic fluid volume and non-stress test1. The last one involves two phase testing by ultrasound and external Doppler monitor. However, this was not only expensive but also time consuming, and causing inconvenience to the patients. This was overcome by the modified BPP, which observe the non stress test to be a short term marker and amniotic fluid index to be a 
long term placental term marker. This method was easy to perform and used less time than BPP. This was a rapid test that did not require highly qualified personnel.

\section{METHODS}

His prospective study was conducted by the department of gynecology of Dr VRK Women's Medical College from August 2016 to Feb 2018. 242 patients with over 34 weeks of gestation and with one or more risk factors were included in the study.

The study protocol was explained to the patient and her relatives in detail and informed consent was obtained. Those unwilling to give the informed consent were excluded from the study.

At 34 weeks of gestation, the intervention can be given immediately in the event of the MBPP score being low. Also, at this age, the respiratory distress of the fetus would be low and the fetal weight would be round $2 \mathrm{kgs}$.

After taking the demographic details, the patients were subjected to detailed physical and clinical evaluation. Modified BPP was done on all the patients. Index of acute fetal hypoxia - the NST was done along with the cardiotocograph (CTG). Amniotic fluid volume was calculated.

\section{RESULTS}

Out of the 242 patients, $68(28.1 \%)$ had gestational hypertension and $42(17.4 \%)$ had intrauterine growth restriction (IUGR). Anemia was seen in 25 (10.3\%) of the patients while a bad obstetrics history was observed in 29 (11.6\%) (Table: 1).

Table: 1: Obstetric history among the patients.

\begin{tabular}{|ll|}
\hline Risk factor & No of cases $(\%)$ \\
\hline Gestational hypertension & $68(28.1 \%)$ \\
\hline Intrauterine growth restriction & $42(17.4 \%)$ \\
\hline Previous LSCS & $32(13.2 \%)$ \\
\hline Anemia & $25(10.3 \%)$ \\
\hline Bad obstetric history & $29(11.6 \%)$ \\
\hline Premature rupture of membranes & $10(4.1 \%)$ \\
\hline Systemic diseases & $9(3.7 \%)$ \\
\hline Malpresenttion & $8(3.3 \%)$ \\
\hline Rh incompatabitlity & $10(4.1 \%)$ \\
\hline Gestational diabetes & $9(3.7 \%)$ \\
\hline
\end{tabular}

According to the fetal non-stress test, majority of the patients (171) were reactive $(70.7 \%)$ while $71(29.3 \%)$ were non-reactive (Figure 1).

Most of the patients (162) had an amniotic fluid index in the normal range i.e. between $8-<25.45$ patients $(18.6 \%)$ had an AFI value of $<6 \mathrm{~cm}$ while $33(13,6 \%)$ had between $6-<8$. Only 2 patients $(0.9 \%)$ had an AFI value of $>24 \mathrm{~cm}$ (Figure 2). $91(53.2 \%)$ patients who were reactive for NST had normal delivery, while 35 (20.5\%) had episiotomy. $44(25.7 \%)$ out of them had caeserian delivery while breech delivery was seen in $1(0.6 \%)$.

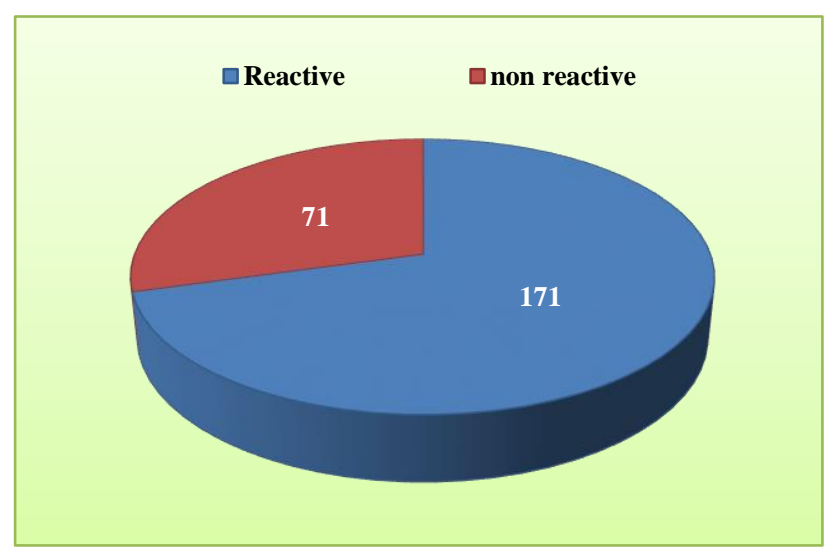

Figure 1: Distribution of the patients according to NST pattern.

There were no patients with breech delivery among those with Non-reactive NST and AFI $\leq 5$, while $1(0.5 \%)$ who had AFI $>5$ had breech delivery. Among the non-reactive NST and AFI $>5$, the most predominant mode of delivery was normal delivery $(54.9 \%, 56.8 \%$ respectively).

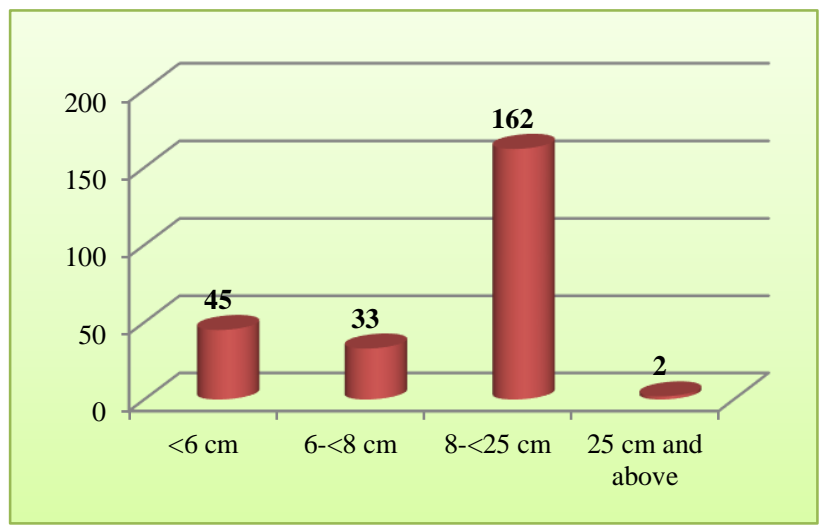

Figure 2: Distribution according to the AFI value.

This was followed by caesarian delivery, $(28.2 \%$ and $22.3 \%$ ). However, in the patients with AFI $\leq 5$, the most common mode of delivery was caesarian delivery (44.4\%), followed by normal delivery $(40 \%)$ (Table: 2 ).

Among the babies with reactive NST, non-reactive NST and AFI $\leq 5$, the most common outcome was low birth weight. Meconium was seen in $23(13.5 \%)$ cases among the reactive NST, 7 (11.5\%) among non-reactive NST, 13 (28.9\%) among $\mathrm{AFI} \leq 5$ and 17 (37.8\%) in $\mathrm{AFI}>5$.

APGAR score $<7$ was observed in $19(11.1 \%) 8(13.1 \%)$ $9(20 \%)$ among Reactive NST, non-reactive NST and AFI $\leq 5$ respectively (Table 3 ). 
Modified BPP score was done for all the patients. The sensitivity of this test was $63.2 \%$ and the specificity was
$98.1 \%$. The positive predictive value was $70.9 \%$, while the negative predictive value was $90.2 \%$ (Table: 4 ).

Table 2: Mode of delivery according to NST pattern and AFI.

\begin{tabular}{|lllll|}
\hline Mode of delivery & Reactive NST (171) & Non-reactive NST (71) & AFI $\leq 5(45)$ & AFI > 5 (197) \\
\hline Normal (130) & $91(53.2 \%)$ & $39(54.9 \%)$ & $18(40 \%)$ & $112(56.8 \%)$ \\
\hline Episiotomy (47) & $35(20.5 \%)$ & $12(16.9 \%)$ & $7(15.6 \%)$ & $40(20.3 \%)$ \\
\hline Caeserian (64) & $44(25.7 \%)$ & $20(28.2 \%)$ & $20(44.4 \%)$ & $44(22.3 \%)$ \\
\hline Breech (1) & $1(0.6 \%)$ & $0(0 \%)$ & $0(0 \%)$ & $1(0.5 \%)$ \\
\hline
\end{tabular}

Table 3: Outcome.

\begin{tabular}{|lllll|}
\hline Outcome of babies & Reactive NST (171) & Non-reactive NST (61) & AFI $\leq 5(45)$ & AFI $>5(197)$ \\
\hline Fetal distress & $18(10.5 \%)$ & $12(19.7 \%)$ & $11(24.4 \%)$ & $19(9.6 \%)$ \\
\hline APGAR score $<7$ & $19(11.1 \%)$ & $8(13.1 \%)$ & $9(20 \%)$ & $18(9.1 \%)$ \\
\hline Meconium & $23(13.5 \%)$ & $7(11.5 \%)$ & $13(28.9 \%)$ & $17(37.8 \%)$ \\
\hline Low birth weight & $21(12.3 \%)$ & $14(23 \%)$ & $19(42.2 \%)$ & $16(8.1 \%)$ \\
\hline Still born/perinatal deatl & $0(0 \%)$ & $2(3.3 \%)$ & $2(4.4 \%)$ & $0(0 \%)$ \\
\hline Admission to NICU & $3(1.8 \%)$ & $11(18 \%)$ & $9(20 \%)$ & $5(2.5 \%)$ \\
\hline
\end{tabular}

Table 4: MBPP score.

\begin{tabular}{|lll|}
\hline & MBPP score & BPP score \\
\hline Sensitivity & $63.2 \%$ & $71.2 \%$ \\
\hline $\begin{array}{l}\text { Specificity } \\
\text { Predictive value of a } \\
\text { positive test }\end{array}$ & $98.1 \%$ & $94.7 \%$ \\
\hline $\begin{array}{l}\text { Predictive value of a } \\
\text { negative test }\end{array}$ & $70.9 \%$ & $78.2 \%$ \\
\hline $\begin{array}{l}\text { Percentage of false } \\
\text { positives }\end{array}$ & $90.2 \%$ & $92.1 \%$ \\
\hline $\begin{array}{l}\text { Percentage of false } \\
\text { negatives }\end{array}$ & $57.1 \%$ & $5.9 \%$ \\
\hline
\end{tabular}

\section{DISCUSSION}

In 1893 itself, Winkel set the limits of the fetal heart rate at 120-160 beats per minute. However, it was in 1950 , when the first heart beat was heard by Phillipe-le-Goust. ${ }^{2}$ Amniotic fluid fluctuations were demonstrated by Gadd in 1966 by amniocentesis and dilution studies. ${ }^{3}$ Correlation of fetal heartrate pattern and neonatal outcome was done by Hon and Quilligan in 1967. ${ }^{4}$ Quantification of faetal activity in patient who were at risk of uteroplacental insufficiency was done by Sadovsky and Waffe in 1973.5 In 1976 , it was suggested by Lee that non-stress test could be a reliable method to predict FHR acceleration and fetal movements. ${ }^{6}$ A multiparameter for assessing the condition of the fetus using four conditions such as foetal movement, tone, breathing and non-stress test was put forth by Manning in $1980 .^{7}$ In 1983 however, a modification of this test was done by Vintzileous and added two more variables, the non-stress test and amniotic fluid index. ${ }^{8}$ The outcome of the fetus on measuring the AFV was shown by
Chamberlain in 1984 and Phelan using a semiquantitative test called amniotic fluid index (AFI) for the assessment of AFV. ${ }^{9,10}$ BPP was modified to MBPP only in the year 1996 by Miller DA. ${ }^{11}$

The BPP uses ultra sound for the assessment of foetal movements, tone, breathing and amniotic fluid volume, with the monitoring of the foetal heartbeat over a 20minute period. MBPP uses the CTG machine for the NST only. If an abnormality occurs, then the BPP is done.

It is very essential in the antepartum foetal surveillance to identify the compromised fetus as early as possible so that timely intervention may be given. Out of the different surveillance methods available, the best would be the one which is capable of not only identifying the fetus at risk, but also is cost effective and easy to perform, with minimal or no risk. Modified BPP is one such test.

Most of the patients in the present study had an amniotic fluid index in the normal range i.e. between $8 \quad-<25$, however, $18.6 \%$ had an AFI value of $<6 \mathrm{~cm}$. This was corroborated by a study by Maurya et al, who reported an AFI value $n$ the normal range in around $65 \%$ of the patients and in around $22 \%$ of the cases, it was below $6 \mathrm{~cm} .^{12}$

$53.2 \%$ patients who were reactive for NST had normal delivery, while $20.5 \%$ had episiotomy in the present study. $25.7 \%$ out of them had caeserian delivery while breech delivery was seen in 1 patient. However, in the patients with AFI $\leq 5$, the most common mode of delivery was caesarian delivery (44.4\%). This was similar to a study by Maurya et al., where the most common 
mode of delivery in cases with AFI $<6 \mathrm{~cm}$ was LSCS. ${ }^{12}$ Yogitha et al, in their study also observed LSCS to be the most common mean of delivery in case of abnormal BPP and AFI values. ${ }^{13}$

Low birth weight was the most common outcome among the new borns in present study, including in the cases where the AFI value was $<6 \mathrm{~cm}$. Fetal distress was seen in $24.4 \%$ of the cases with low AFI value, followed by APGAR score of $<7$ in $20 \%$ of the cases. Similar results were observed in a study by Raparthy et al., where $16.6 \%$ of the patients had an APGAR score of $<7 .{ }^{14}$

In the present study, we had evaluated the efficacy MBPP in prediction of the neonatal outcome vide sensitivity, specificity, positive predictive value and negative predictive value. The sensitivity of this test was $63.2 \%$ and the specificity was $98.1 \%$. The positive predictive value was $70.9 \%$, while the negative predictive value was $90.2 \%$. In comparison, BPP had a better sensitivity while the specificity was a little lesser. The predictive false positive and negative value in the case of BPP was slightly higher than MBPP, though not significant. Similar values were reported by Jamal et al, who found no significant difference in the specificity, sensitivity, PPV and NPV in the case of BPP and MBPP. ${ }^{15}$ Young et al and Miller et al also showed similar results with comparable BPP and MBPP values. ${ }^{11,16}$

\section{CONCLUSION}

Present study shows that BPP and MBPP are both comparable to each other. Since BPP is a lengthier and time-consuming test requiring expertise. MBPP, which is a simpler test can be substituted. However, the final decision still remains with the attending gynecologist.

Funding: No funding sources

Conflict of interest: None declared

Ethical approval: The study was approved by the Institutional Ethics Committee

\section{REFERENCES}

1. Manning FA, Platt LD, Sipos L. Antepartum fetal evaluation: development of a fetal biophysical profile. Am J Obstet Gynecol. 1980;136(6):787-95.

2. Gibbs D. Foetal monitoring in practice. $3^{\text {rd }}$ ed. Clinical assessment and practice, Canada;2000;11:210.

3. Gadd RL. The volume of liquor amni in normal and abnormal pregnancy. J Obstet Gynecol. 1966;73(1):11-22.
4. Hon EH, Quilligan EJ. The classification of foetal heart rate. II a revised working classification. Conn Med. 1967;31(11):779-84.

5. Sadovsky E, Yaffe H. Daily foetal movement recording and foetal prognosis. Obstet Gynaecol. 1973;41(6):845-50.

6. Lee CY, Diloreto PC, Olane JM. The study of FHR acceleration patterns. Obstet Gynaecol. 1975;45(2):142-6.

7. Read JA, Miller FC. FHR acceleration response to acoustic stimulation as a measure of foetal well being. Am J Obstet Gynaec. 1977;129(5):512-7.

8. Vintzileous AM, Campbell WA, Ingardie CJ, Nochimson DJ. The foetal BPP and it predictive value. Obstet Gynaecol. 1985;62:217.

9. Chamberlain PF, Manning FA, Morrison I. Ultrasound evaluation of amniotic fluid volume I the relationship of marginal and decreased amniotic fluid volumes to perinatal outcome. Am J Obstet Gynaecol. 1984;150(3):245-9.

10. Phelan JP, Ahn MO, Smith CV, Rutherford SE, Anderson E. AFI measurements during pregnancy. J Reprod Med. 1987;32(8):601-4.

11. Miller DA, Rabello YA, Paul RH. The MBPP: antepartum testing in 1990s. Am J Obstet Gynaecol. 1996;174(3):812-7.

12. Maurya A, Kushwah V. Modified Biophysical Profile and Fetal Outcome in High Risk Pregnancy. Sch J App Med Sci. 2014;2(1C):283-90.

13. Yogitha V, Sanjay SC, Shukla AK. Modified biophysical profile as an antepartum surveillance test in high risk pregnancy: a prospective comparative study with conventional biophysical profile. J Res Radiodiag Teleradiol Imaging. 2016;2(1):18-25.

14. Raparthy S, Sunitha C. Study of Oligohydramnios Cases by Modified Biophysical Profile and Their Perinatal Outcome. J Dent Med Sci. 2014;1(9):62-69

15. Jamal A, Marsoosi V, Noori LE. A prospective trial of the fetal biophysical profile versus modified biophysical profile in the management of high risk pregnancies. Acta Medica Iranica.2007;45(3):204-8

16. Young D, Delaney T, Nogue K. Randomized trial of original, modified and selective fetal biophysical profiles. Am J Obstet Gynecol. 2003;187:143.

Cite this article as: Vanamala VG, Rachel A, Pakyanadhan S, Abraham SP. Biophysical profile and modified biophysical profile in predicting the fetal outcome. Int J Reprod Contracept Obstet Gynecol 2018;7:3516-9. 